\title{
EXPOSIÇÃO DA VIDA PRIVADA EM REDES SOCIAIS: MOTIVAÇÕES E CONSEQUÊNCIAS
}

\author{
Rogerio do Amaral \\ Universidade do Oeste Paulista - UNOESTE, Faculdade de Comunicação Social, Presidente Prudente, SP. E-mail: \\ professorrgamaral@gmail.com
}

\section{RESUMO}

Este artigo visa compreender como a vida real é construída na rede social Facebook e de que maneira se dá a espetacularização do privado, além de levantar os principais tipos de publicização da vida privada no Facebook; e, identificar o valor atribuído à publicização da vida pelo usuário virtual de redes sociais. Quanto à metodologia, o projeto emprega uma abordagem qualitativa, por meio dos métodos de análise das redes sociais. A coleta de dados empregará a aplicação de um questionário online e a observação participante em páginas do Facebook, com a intenção de compreender como a vida privada é espetacularizada na rede social e quais os resultados que tal publicização gera para a vida do usuário que realiza tal prática.

Palavras-chave: Vida privada; Publicização; Espetáculo; Redes Sociais; Facebook.

\section{EXPOSITION OF THE PRIVATE LIFE IN SOCIAL NETS: MOTIVATIONS AND CONSEQUENCES}

\begin{abstract}
This article aims to understand how the real life is constructed in the social net Facebook and howthe spectacularization of the private occurs, beyond raising the main types of publicization of the private life on the Facebook; and, to identify the value attributed to the publicization of the life by the virtual user of social nets. As far as the methodology, the project uses a qualitative boarding, by means of the methods of analysis of the social nets. The collection of data will use the application of an online questionnaire and the participant observation in pages of the Facebook, with the intention to understand how the private life is spectacularized in the social net and which results that such publicization generates for the life of the user who carries through such practice.
\end{abstract}

Keywords: Private life; Publicization; Spectacle; Social nets; Facebook 


\section{INTRODUÇÃO}

O avanço tecnológico alterou as tecnologias da comunicação, originando novos meios de comunicação, como a internet, um espaço marcado pela produção de conteúdo em um ambiente virtual infinito, caracterizado pela instantaneidade que alterou a percepção de tempo e espaço que tínhamos antes desse novo formato. Outro fator marcante da internet refere-se à forma rápida como essa mídia de comunicação mediada pelo computador se expandiu, já que desde o momento em que se tornou um produto comercial, duas décadas foram suficientes para sua plena consolidação. Nesse ambiente, as redes sociais tornaram-se as ferramentas mais efetivas no que se refere à influência exercida sobre o usuário. Os jovens e adolescentes são os maiores usuários dessa ferramenta, no entanto, esse espaço já conquistou adeptos em todas as demais faixas etárias. O advento das redes sociais trouxe inúmeras benesses para o campo da relação interpessoal, com ênfase na instantaneidade da comunicação, a possibilidade de relacionamento com um grande número de pessoas, assim como a possibilidade de reunir amigos e familiares espalhados pelos quatro cantos do planeta. No entanto, ao lado dos aspectos positivos sempre aparecem também os fatores negativos. Nas redes sociais, um dos principais fatores de preocupação é o excesso de exposição por parte dos usuários. Nesse ambiente, a sensação predominante é de que o sujeito se esquece da necessidade de impor limites ao quanto sua vida ficará exposta para os demais usuários, dessa forma, seja por meio de fotografias e vídeos ou textos, cada vez mais a vida cotidiana se transforma num grande espetáculo apreciado por milhões e milhões de usuários.

A partir dessa visão de domínio que a sociedade contemporânea exerce sobre os sujeitos, nos deparamos com o conceito de "sociedade excitada", utilizado por Türcke (2004, p. 62), segundo o qual os eventos sensacionais "[...] são capazes de seduzir a massa a tal ponto que servem como válvulas de escape para todas as possíveis frustrações." A ideia de sensação relaciona-se ao fato de ser percebido, pois de acordo com Türcke $(2004$, p. 63) "o que não é percebido é um nada; quem não é percebido é um ninguém." Mas, para a sociedade esse ser percebido não tem nenhuma relação com ser independente, e sim com uma repetição de padrão estabelecida pelos grupos sociais dos quais participamos. Nota-se que a sensação provocada pela sociedade contemporânea tem apenas a intenção de conduzir o sujeito no caminho estipulado pela indústria cultural, isto é, pretende-se colocar o indivíduo em contato com sua produção em série. Por isso, Türcke (2010, p. 9) afirma que o "[...] progresso tecnocientífico minou tudo aquilo que pareceu ser natural. [...] Nada é obvio mais. [...] o inconstante se tornou constante: o estado de uma inquietude geral, de excitação, de efervescência." E continua, "as sensações estão a ponto 
de se tornar as marcas de orientação e as batidas do pulso da vida social como um todo." (2010, p. 14). Vivemos um tempo e um espaço que nos provoca sensações em cima de sensações, mas elas não nos pertencem e são estimuladas pela técnica, através da manipulação de diferentes ferramentas, principalmente aquelas que podem controlar os bens culturais de uma sociedade, como os meios de comunicação.

Na visão de Debord (1997, p. 13) essa época marcada pela sensação é definida como sociedade do espetáculo, pois em "toda a vida das sociedades nas quais reinam as modernas condições de produção se apresenta como uma imensa acumulação de espetáculos. Tudo o que era vivido diretamente tornou-se uma representação." De acordo com o Debord $(1997$, p. 16) “o espetáculo se apresenta como uma enorme positividade, indiscutível e inacessível. Não diz nada além de 'o que aparece é bom, o que é bom aparece'. A atitude que por princípio ele exige é da aceitação passiva que de fato, ele já obteve por seu modo de aparecer sem réplica, por seu monopólio da aparência." E acrescenta que "o espetáculo não é um conjunto de imagens, mas uma relação social entre pessoas, mediada por imagens." (1997, p. 3). Portanto, essa nova sociedade impõe aos seus indivíduos a necessidade de se mostrar para os demais membros, mas Debord (1997) acrescenta que esse se mostrar não é um ato de vontade do sujeito, mas uma representação das imagens espetaculares oferecidas pela sociedade para serem disseminadas e consumidas pelos indivíduos. Ou seja, os grupos sociais denominados de tribos, não são produtores de uma nova forma de pensar e agir.

Santos (2000, p. 298) referindo-se a Nishitani afirma que "[...] o progresso da ciência e da tecnologia caminha em sentido oposto ao do progresso da moralidade da conduta humana." No entanto, em outra passagem, ele afirma que "o mais fascinante [...] é dar-se conta de que a satisfação do desejo desse sujeito que tenta escapar da mecanização se faz cada vez mais intensificando o próprio processo de mecanização." Ou seja, a técnica trouxe sérios problemas morais, mas a sociedade tem que encontrar mecanismos para resolver tais problemas, já que a técnica não desaparecerá mais do nosso espaço contemporâneo. Por outro lado, quanto mais o sujeito tenta se afastar desse domínio das tecnologias, mais ele se vê preso nessa teia tecnológica.

Quanto à presença da técnica em nosso meio, Giacóia Junior (2003, p. 52) afirma que “[...] algo de exagerado, irracional, patogênico se insere no atual relacionamento com a técnica." Segundo o autor "Os homens estão inclinados a considerar a técnica como a coisa mesma, como fim em si mesmo, como uma força com essência própria, e esquecer que ela é o braço prolongado do homem." Na visão de Giacóia Junior , quando propomos analisar o papel que a técnica assumiu em nossas vidas, é necessário também avançar para a maneira como o homem se apoderou da 
técnica para impor seu domínio sobre os demais sujeitos. Não é a técnica que domina a sociedade contemporânea, mas a forma como o homem a utiliza que permite tantos mecanismos de controle.

Quanto à nova configuração do tempo gerado pelo emprego da técnica, Pelbart (2000, p. 32) diz que "[...] a produção não fica centrada na fábrica, ela invade o tecido urbano, os domicílios, se pulveriza e se mistura com o tempo livre." Para o autor "[...] a pós-modernidade comporta a presença do eixo consumidor/mercadoria em todos os pontos do espaço-tempo social." (2000, p. 33). Assim, percebemos que o espaço privado do sujeito já não existe mais, pois as técnicas de informação, produção e consumo usam seus mecanismos para ultrapassar qualquer barreira que atrapalhe a realização do seu objetivo de dominação. Pelbart $(2000$, p. 34) diz ainda que "o tempo livre virou um tempo escravizado, tempo investido em ganhar tempo. Se pensarmos na informática doméstica, nessa fronteira entre trabalho, entretenimento, hipnose, fetiche, num esforço constante para otimizar o próprio desempenho, temos disso um exemplo banal [...]." Sobre a redefinição do tempo presente e do espaço em que vivemos, Virilio (1998, p. 130) comenta que "o livre, o tempo real, é um tempo mundial." Para o autor (1998, p. 131) “[...] quando entramos no tempo mundial, ingressamos no virtual. Ou seja, o atual cessa em proveito da virtualidade." Essa visão de Virilio, leva-nos a uma reflexão sobre a realidade e os mecanismos que devemos ativar para separar aquilo que é construído no campo do real e o que é fruto do campo virtual, uma representação da realidade.

Os mecanismos de domínio da técnica se dão por meio de todos os sentidos humanos, de forma que não exista um sujeito que não possa ser contemplado pelo projeto de sociedade imposta pela sociedade de controle contemporânea, portanto, para confrontar esse controle o sujeito de hoje precisa ativar distintos mecanismos de defesa, pois as sensações experimentadas ainda estão alguns passos a nossa frente. Participar desse novo espaço é o eldorado da modernidade, no entanto isso não é algo simples, pois de acordo com Dibie (2009, p. 244) “nunca uma cultura, a cibercultura, fez tantas exigências. [...] nunca estivemos diante de uma cultura protocolar tão exigente, na qual, para que funcione, para que o diálogo homem-máquina seja possível, é necessário se curvar à disciplina de uma máquina." Para o autor "a particularidade do cibernauta é [...] ser um viajante veloz e rápido." (2009, p. 251). A sociedade da informação vende um ideal de perfeição, mas para isso você deve estar apto a se curvar às regras do jogo, que na contemporaneidade exige uma exposição pública demasiada. Diante do exposto, o presente trabalho tem o objetivo de compreender como a vida real é construída na rede social Facebook e 
de que maneira se dá a espetacularização do privado. Pretende-se também levantar os principais tipos de publicização da vida privada no Facebook.

\section{METODOLOGIA}

Para a execução desse artigo empregou-se abordagem qualitativa, visando à compreensão em profundidade dos dados coletados por meio da aplicação de um questionário eletrônico, composto por 16 questões e enviado às 1.212 pessoas que estabeleciam relação de amizade com o autor desse trabalho na página do Facebook. Além da aplicação do questionário, essa pesquisa também realizou uma observação participante em 30 páginas de usuários do Facebook que não apresentavam vínculo de amizade com o autor. A escolha dessas 30 páginas baseou-se em número de amigos que os perfis possuíam. Dessa forma, foram escolhidas seis páginas de usuários para cinco grupos: até 250 amigos; de 250 a 500 amigos; de 500 a 1.000; de 1.000 a 2.000 amigos; e acima de 2.000 amigos. Os dados coletados por meio do questionário e da observação participante foram cruzados vislumbrando construir o perfil do usuário da rede social Facebook, no que se refere, à publicização espetacular da vida privada nesse ambiente virtual. Quanto ao questionário citado, o mesmo foi cadastrado no Comitê de Ética em Pesquisa (CEP), sediado na Universidade do Oeste Paulista (Unoeste), de Presidente Prudente. Depois de avaliado, o questionário foi aprovado e está registrado na Plataforma Brasil sob o número CAAE 44436315.8.0000.5515.

\section{RESULTADOS}

O questionário citado na metodologia foi enviado a 1.212 pessoas que tinham relação de amizade com o autor do artigo. Desse total, 323 se dispuseram a responder o mesmo, o que foi possível por meio da plataforma do Google Formulários. Os resultados apresentados pelo questionário mostram o seguinte cenário quanto ao uso da rede social Facebook: aproximadamente 33\% dos usuários têm até 21 anos e aproximadamente $45 \%$ têm entre 22 e 30 anos. Os demais estão acima dos 30 anos. Quanto ao tempo de uso do Facebook, 61,5\% o fazem há mais de cinco anos, enquanto $24,3 \%$ usam a página há mais de três anos, enquanto $93,4 \%$ responderam que o Facebook não foi a primeira rede social com a qual tiveram contato. Nesse caso, 250 respondentes citaram o Orkut como o primeiro contato com redes sociais. 92,9\% dos respondentes afirmaram possuir conta em outras redes sociais, com destaque para os 97,3\% desses usuários com conta no Whatsapp, os $75,4 \%$ no Instragram, os $61,4 \%$ no Youtube e os $54,6 \%$ no Twitter. Essas redes sociais têm foco específico e são usadas por isso, já que a maioria 
reconhece que o Facebook disponibiliza todas as funções das outras redes. Mais de $89 \%$ das pessoas acessam a rede do celular e $37,6 \%$ do trabalho. Mais de $85 \%$ acessa o perfil todos os dias e $94,2 \%$ adotam critérios para adicionar amigos, dos quais $85,6 \%$ são conhecidos, $70,4 \%$ amigos de trabalho ou estudo, $53,3 \%$ amigos fora da rede social e mais de $45 \%$ amigos da família. $67 \%$ respondentes permitem que todos os amigos visualizem suas postagens, enquanto apenas $1 \%$ limita a visualização a menos de $10 \%$ dos amigos. $71,9 \%$ realizam apenas uma postagem por dia na página e $24,4 \%$ de duas a cinco postagens. $45,6 \%$ dos respondentes assumiram compartilhar informações pessoais na rede, enquanto $88,9 \%$ reconheceram que os amigos postam fatos particulares no Facebook. Quando questionados sobre o que postam nesse espaço, 80,3\% disseram postar fotos pessoais, $49,3 \%$ casos de sucesso, $31,9 \%$ luto e $25 \%$ início e fim de relacionamento. Apenas $16,6 \%$ disseram ter tido algum problema por causa de postagens pessoais na página, mas $47,9 \%$ afirmaram conhecer pessoas que tiveram problemas por esse motivo. $63,8 \%$ afirmaram temer a exposição na rede social, no entanto questionados por que mesmo assim o fazem, uma gama de entrevistados disseram agir de forma automática e outros citaram que enquanto nada de ruim acontece, eles continuam executando a ação. Quanto às perguntas abertas, as respostas evidenciaram que o usuário acha desnecessário e até mesmo perigoso o excesso de exposição nessa rede social, o que deveria criar no usuário uma conscientização sobre o que realmente é necessário compartilhar. Porém, também tivemos respostas defendendo essa atitude de exposição, afirmando que a rede social foi criada para isso e que quem não concorda deve encerrar seu perfil. Sobre os motivos para o uso do Facebook, predomina nas respostas manter-se informado sobre o cotidiano, contatar amigos e familiares e entretenimento.

Quanto à observação participante de trinta perfis do Facebook, o resultado aponta que os jovens são os responsáveis pela maioria das interações nos espaços, assim perfis de jovens apresentam ações constantes na página, enquanto pessoas mais velhas agem de forma mais moderada e até mesmo esporádica. Também se evidenciou que o número de amizades interfere na realização de interações, dessa forma perfis acima de 1.000 amigos também são mais movimentados, enquanto perfis com poucos amigos quase não interagem. Quanto ao uso do Facebook para divulgação de trabalho, observou-se que esses perfis têm o número máximo de amigos permitidos pelo sistema. Essa observação também localizou a postagem de um vídeo que mostra um policial sendo alvejado por um tiro, quando instalava uma câmera de vídeo em uma comunidade, fato que permite vislumbrar a presença da exposição pessoal sem nenhum tipo de critério na rede social Facebook. 


\section{DISCUSSÃO}

Os resultados apresentados acima nos permitem depreender que apesar das vastas possibilidades de emprego das redes sociais, o espaço é amplamente dominado pelo entretenimento, principalmente, interações entre amigos e familiares. Assim, o Facebook torna-se um ambiente norteado por postagens de cunho pessoal, envolvendo tanto texto como imagens, com pouquíssimas interações de cunho opinativo, com a intenção de discutir questões relevantes para a vida do indivíduo como política e cultura. No Facebook o que predomina é a construção de uma personagem de destaque, capaz de atrair o máximo de atenção possível dos demais usuários desse espaço. A busca por essa visibilidade constante, comportamento padrão imposto pela sociedade do espetáculo, cuja característica básica é a necessidade do sujeito despertar a atenção alheia, se efetiva plenamente nesse espaço virtual, cujo funcionamento elimina as barreiras do espaço e do tempo e permite ao usuário atingir um número cada vez maior de pessoas.

Os dados do questionário nos evidenciam que é mais fácil para o usuário inferir a exposição nas postagens de seus interlocutores do que em seu próprio ato, tanto que mais da metade dos respondentes afirmaram não realizar postagem de tom pessoal, mas aproximadamente $80 \%$ citaram que postam fotos pessoais, ou seja, temos aí uma contradição, já que parte dos usuários não considera postar foto como forma de exposição. Também verificamos que o Facebook é espaço para que o usuário compartilhe diferentes tipos de sentimentos, assim nos deparamos nessa página tanto com fatos positivos como também com aspectos negativos que envolvem a vida das pessoas.

Os usuários que mais participam desse ambiente são os jovens. Estes, devido ao envolvimento mais próximo com a tecnologia emergem nas características das redes sociais e norteiam suas vidas de acordo com tais características. Dessa forma, perfis jovens mostram recheados de fotos de foro íntimo, seja do jovem sozinho ou acompanhado pelos amigos, nas mais variadas situações, tanto que um dos perfis analisados mostrou um adolescente postando foto com um grupo de amigos, todos felizes, após serem assaltados durante um passeio. Para esses usuários não há limites, tudo que acontece seja bom ou ruim deve ser compartilhado com o outro. As redes sociais, em especial o Facebook, se transformaram no diário do jovem contemporâneo, porém, com uma especificidade distinta, já que no presente, as anotações do diário são compartilhadas com o máximo possível de pessoas.

Dentre os principais fatores de exposição, a imagem através de fotografias e mais recentemente vídeos ainda ocupa o primeiro lugar. Porém, os usuários da rede social também empregam bastante a postagem textual para relatar o que tem acontecido em suas vidas. Dentre 
essas postagens, o ambiente sempre apresenta mensagens direcionadas de forma indireta a outras pessoas, o que muitas vezes gera discussão pública. A exposição, como já citado, não tem parâmetro, assim uma sequência de postagens pode misturar textos e mensagens de cunho religioso, com a foto da balada e uma bebida na mão. Ao mesmo tempo em que um usuário reclama de algo que aconteceu de ruim em sua vida, ele já compartilha um meme engraçado sobre um fato cotidiano. Tudo vai para a página da rede social, ao mesmo tempo, misturado, sem critérios. O que vale nesse ambiente é aparecer para os demais usuários, despertar a atenção a qualquer custo, o que valida o uso de diferentes recursos para aumentar a quantidade de curtidas de sua ação nesse espaço.

\section{CONSIDERAÇÕES}

Dessa forma, percebemos que a vida real apresentada no Facebook é mascarada pela presença de uma personagem em busca de destaque diante dos demais participantes. Assim, essa personagem pode empregar duas linhas de atuação. A primeira linha é marcada pela espetacularização do sucesso, que consiste no usuário da rede social que só partilha com seus interlocutores os bons momentos de sua vida, da mesma forma que seus textos sempre são marcados por mensagens positivas dando a entender que sua vida é um verdadeiro mar de rosas, mesmo que as pessoas próximas saibam que essa exposição virtual não condiz com a verdade. Já a segunda linha traz o usuário que se vende como um coitado, perseguido e sem sorte. Trata-se de um personagem de novela mexicana, sempre envolto em dramas e reclamando de tudo e de todos, com o objetivo de gerar pena em seus interlocutores. Esse tipo de usuário faz de sua linha do tempo, um divã, e espera encontrar entre seus amigos, aqueles que ajam com psicólogos, dispostos a lhe tirar desse mar de tristezas.

Seja mostrando uma felicidade inexistente ou exagerando no drama, o que realmente acontece no Facebook é a exposição demasiada e desmedida de questões privadas em forma de espetáculo, pois não basta expor sua vida, o usuário precisa fazer isso em forma de show, o mais chamativo possível, garantindo que o outro olhe para ele. O estudo sobre espetacularização e publicização do privado atrelado a redes sociais nos mostra que essa exposição demasiada é motivada por uma sociedade contemporânea marcada pela prática consumista que invadiu a vida humana e transformou o sujeito em um produto que precisa ser vendido a qualquer custo. No entanto, o sujeito moderno ainda não tem noção das consequências desse ato excessivo de publicização, tanto que o questionário aplicado trouxe respostas defendendo essa prática como algo natural, sem se preocupar com a necessidade do homem de ter uma parte de sua vida 
privada, resguardada dos olhares alheios. A modernidade não quer nada resguardado, por isso, cada dia mais incentiva que o sujeito se mostre e se venda. Nesse sentido, as redes sociais contribuíram muito para que o indivíduo possa cada vez mais se autopromover para seus interlocutores.

\section{REFERÊNCIAS}

DEBORD, Guy. A sociedade do espetáculo. Tradução de Estela dos Santos Abreu, São Paulo: Contraponto, 1997.

DIBIE, Pascal. Ondulações paranoides de uma época. In: NOVAES, Adauto (Org.). A condição humana: as aventuras do homem em tempos de mutações. São Paulo: Agir Editora, 2009.

GIACOIA JUNIOR, Oswaldo. Ética, técnica, educação. In: MORAES, Eduardo Jardim de; BIGNOTTO, Newton (Orgs.). Hannah Arendt: diálogos, reflexões, memórias. Belo Horizonte: Editora UFMG, 2003.

PELBART, Peter Pál. A vertigem por um fio: políticas da subjetividade contemporânea. São Paulo: lluminuras, 2000.

SANTOS, Laymert Garcia dos. Tecnologia, perda do humano e crise do sujeito do direito. In: OLIVEIRA, Francisco de; PAOLI, Maria Célia (Orgs.). Os sentidos da democracia: políticas do dissenso e a hegemonia global. 2. ed. Petrópolis-RJ: Vozes; Brasília: NEDIC, 2000.

TÜRCKE, Christoph. Sociedade da sensação: a estetização da luta pela existência. In: ZUIN, Antonio A. S.; PUCCI, Bruno; RAMOS-DE-OLIVEIRA, Newton (Orgs.). Ensaios frankfurtianos. São Paulo: Cortez, 2004.

TÜRCKE, Christoph.Sociedade excitada: filosofia da sensação. Tradutores Antonio A. S. Zuin et al. Campinas-SP: Editora da Unicamp, 2010.

VIRILIO, Paul. Motores da história. In: ARAUJO, Hermeres Reis de (Org.). Tecnociência e cultura: ensaios sobre o tempo presente. São Paulo: Estação Liberdade, 1998. 